\title{
Optic Nerve Sheath Diameter in Acute Liver Failure: A Prospective Cohort Study
}

\author{
Filipe S. Cardoso ${ }^{a}$ Rui Pereira ${ }^{a}$ Rui Moreno ${ }^{b}$ Constantine J. Karvellas ${ }^{c}$ \\ Nuno Germano ${ }^{\text {a }}$ \\ antensive Care Unit, Curry Cabral Hospital, Lisbon, Portugal; b Neurointensive Care Unit, São José Hospital, \\ Lisbon, Portugal; ' Department of Critical Care, University of Alberta Hospital, Edmonton, AB, Canada
}

\section{Keywords}

Optic nerve $\cdot$ Cerebral edema $\cdot$ Liver failure

\section{Abstract}

Introduction: Acute liver failure (ALF) is a rare disease that may lead to cerebral edema and death. An increased optic nerve sheath diameter (ONSD) may reflect an early increase in intracranial pressure. We assessed the feasibility and safety of the ONSD measurement and its association with outcomes in patients with ALF. Methods: This was an open-label prospective cohort study including adult patients with ALF admitted to a liver-specialized intensive care unit (ICU) in an academic center between October 2018 and February 2020 (among 24): 20 as intention-to-treat and 17 as per-protocol analyses. The ONSD measurement (primary exposure) used an ultrasound transducer (3 determinations on each eye per patient). The primary outcome was hospital mortality. $\boldsymbol{R} \boldsymbol{e}$ sults: Among the 20 patients, 11 (55.0\%) were females and the mean age was $45 \pm 16$ years. On the day of ONSD measurement (median 32.4 h post-ICU admission; IQR 19.8-59.8): 8 patients (40.0\%) were in a coma, the mean international normalized ratio (INR) was $3.3 \pm 1.4$, median bilirubin was

karger@karger.com www.karger.com/pjg

Karger $\stackrel{\text { ' }}{5}$

BOPEN ACCESS
(C) 2020 Sociedade Portuguesa de Gastrenterologia Published by S. Karger AG, Basel

This article is licensed under the Creative Commons AttributionNonCommercial-NoDerivatives 4.0 International License (CC BYNC-ND) (http://www.karger.com/Services/OpenAccessLicense) Usage and distribution for commercial purposes as well as any distribution of modified material requires written permission.
$12.3 \mathrm{mg} / \mathrm{dL}$ (IQR 4.7-24.5), mean ammonia was $163 \pm 101$ $\mu \mathrm{mol} / \mathrm{L}$, and mean SOFA score was $11 \pm 5$. The mean bilateral ONSD was $5.6 \pm 0.7 \mathrm{~mm}$, with a very good correlation between right and left eyes (Pearson's $r=0.90)$. Ten $(50.0 \%)$ patients were transplanted and $13(65.0 \%)$ patients survived the hospital stay (all with a 2-month extended Glasgow Outcome Scale of 8). The mean ONSD was significantly higher for hospital non-survivors than survivors both in the intention-to-treat ( 6.2 vs. $5.3 \mathrm{~mm} ; p=0.004$ ) and per-protocol (6.2 vs. $5.2 \mathrm{~mm} ; p=0.004$ ) analyses. No adverse effects from ONSD measurements were reported. Conclusions: In patients with ALF, a higher ONSD was associated with higher hospital mortality. ONSD measurement is feasible and safe and may have prognostic value.

(C) 2020 Sociedade Portuguesa de Gastrenterologia Published by S. Karger AG, Basel

\section{Diâmetro da baínha do nervo óptico na falência hepática aguda: um estudo coorte prospectivo}

Palavras-chave

Nervo óptico · Edema cerebral · Falência hepática 


\section{Resumo}

Introdução: A falência hepatica aguda (ALF) é uma doença rara que pode complicar com edema cerebral e morte. O aumento do diâmetro da bainha do nervo óptico (ONSD) pode reflectir um aumento precose da pressão intracraniana. Avaliámos a viabilidade e segurança da medição do ONSD e a sua associação com os resultados de doentes com ALF. Métodos: Coorte prospectivo aberto incluindo doentes adultos com ALF admitidos numa unidade de cuidados intensivos (ICU) especializada em fígado entre 10/2018 e 02/2020 (em 24): 20 como análise intenção-de-tratar e 17 como análise por-protocolo. A medição do ONSD (exposição primária) foi realizada com um transdutor ultra-sónico (3 medições em cada olho por doente). O resultado primário foi a mortalidade hospitalar. Resultados: Entre 20 doentes, 11 (55.0\%) eram mulheres e a idade média (SD) foi 45 (16) anos. No dia da medição do ONSD (mediana (IQR) de 32.4 (19.8-59.8) horas pós admissão na ICU): coma em 8 (40.0\%) doentes, INR médio (SD) de 3.3 (1.4), bilirrubina mediana (IQR) de 12.3 (4.7-24.5) mg/dL, amónia média (SD) de 163 (101) $\mu \mathrm{mol} / \mathrm{L}$, e SOFA médio (SD) de 11 (5). O ONSD bilateral médio (SD) foi de $5.6(0.7) \mathrm{mm}$, com boa correlação entre os olhos (Pearson $r=0.90)$. Dez (50.0\%) doentes foram transplantados e 13 (65.0\%) sobreviveram à hospitalização (todos com escala de Glasgow Outcome aos 2 meses de 8). O ONSD médio foi significativamente maior nos não-sobreviventes do que nos sobreviventes quer na análise intenção-de-tratar (6.2 mm vs. $5.3 \mathrm{~mm} ; p=0.004$ ) quer na análise por-protocolo $(6.2 \mathrm{~mm}$ vs. $5.2 \mathrm{~mm} ; p=$ 0.004). Não se registaram efeitos adversos. Conclusões: Em doentes com ALF, maior ONSD esteve associado com maior mortalidade hospitalar. A medição do ONSD é viável, segura, e poderá ter valor prognóstico.

(c) 2020 Sociedade Portuguesa de Gastrenterologia Publicado por S. Karger AG, Basel

\section{Introduction}

Acute liver failure (ALF) is a rare disease with high mortality $[1,2]$. Prognosis has been associated with etiology, clinical course, treatment of organ failures, early referral to specialized centers, and timely liver transplantation (LT) [3-6]. Patients with ALF and hyperacute ( $\leq 7$ days from jaundice to hepatic encephalopathy [HE]) or acute (8-28 days) clinical course, contrary to subacute ( $>$ 28 days to $\leq 26$ weeks), often present with a severe systemic inflammatory response and are at increased risk of cerebral edema, intracranial hypertension ( $\mathrm{ICH})$, and death from tonsillar herniation [7]. Cerebral edema in
ALF may be related to the accumulation of ammonia, lactate, and other inflammatory mediators causing cerebral cell dysfunction $[8,9]$.

The incidence of ICH in ALF decreased from $70-80 \%$ in the 1980 s to $<20 \%$ in the 2000 s, largely because of optimized management in the intensive care unit (ICU) [10]. However, ICH is still concerning as a timely diagnosis is difficult. ICH expression on clinical examination or computed tomography (CT) scan is often late. Furthermore, these patients may be unstable to undergo a CT scan.

While the gold standard for ICH diagnosis requires an intracranial catheter, the perceived risk of bleeding or infection in patients with ALF often prompts clinicians to avoid it [11]. Instead, serum ammonia levels $\geq 100-150$ $\mu \mathrm{mol} / \mathrm{L}$ have been associated with increased risk of cerebral edema and ICH $[12,13]$.

An enlarged optic nerve sheath diameter (ONSD) may reflect elevated intracranial pressure (ICP) being transmitted to the perineural subarachnoid space $[14,15]$. ONSD measurement by ultrasound has been reliable to diagnose ICH in neurocritically ill patients at the bedside $[16,17]$. Accordingly, we hypothesized that ONSD may be useful to detect early cerebral edema in ALF. The objectives of this study were to: (1) assess the feasibility and safety of ONSD measurement in patients with ALF, and (2) evaluate the association of ONSD with these patients' outcomes.

\section{Materials and Methods}

\section{Study Design and Setting}

This was a pilot open-label prospective cohort study including patients admitted to ICUs at the Central Lisbon University Hospital Center (CLUHC) in 2 periods: (1) a training period including patients with traumatic brain injury (TBI) in a neuro-specialized ICU at São José Hospital (SJH) from September 1, 2018 to September 30, 2018; (2) an intervention period including patients with ALF in a liver-specialized ICU at Curry Cabral Hospital $(\mathrm{CCH})$ between October 1, 2018 and February 29, 2020.

\section{Participants}

The inclusion criteria for the training period were: (1) age $\geq 18$ years, and (2) TBI with cerebral edema on CT scan (Fig. 1). The exclusion criteria for the training period were: (1) ICU stay $<24 \mathrm{~h}$, (2) co-existent optic nerve disease, (3) co-existent liver disease, or (4) previous LT. The inclusion criteria for the intervention period were: (1) age $\geq 18$ years, and (2) ALF. The exclusion criteria for the intervention period were: (1) ICU stay $<24 \mathrm{~h},(2)$ co-existent optic nerve disease, or (3) previous LT.

Definitions and Interventions

General Definitions

TBI was defined as any brain lesion due to an external force [18]. Coma was defined as Glasgow Coma Scale (GCS) $\leq 8$ [18]. 


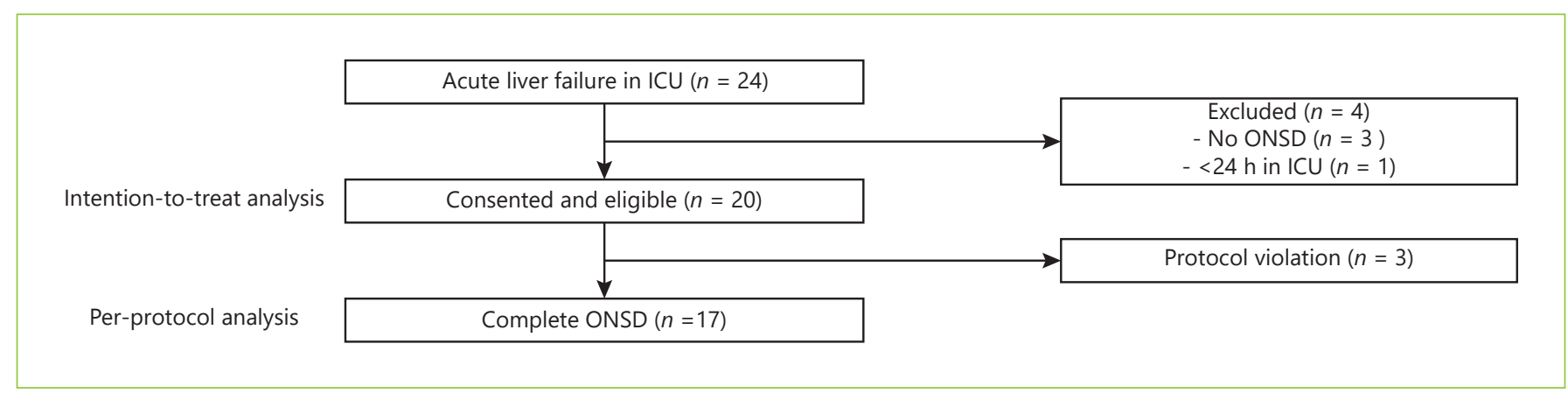

Fig. 1. Flowchart of patients with ALF included and excluded from the study.

Cerebral edema features on CT scan included sulci effacement, midline deviation, or cerebral herniation [19].

ALF was defined as: INR $\geq 1.5$; any grade of HE (West Haven criteria); no cirrhosis, and duration $\leq 26$ weeks $[1,2]$. All patients with ALF were treated with n-acetyl-cysteine $(150 \mathrm{mg} / \mathrm{kg} /$ day for $\leq 5$ days). All patients with TBI or ALF with suspected or confirmed cerebral edema were treated as per the ICP protocol (online suppl. Table S1; for all online suppl. material, see www.karger. com/doi/10.1159/000511646). HE treatment included laxatives (lactulose or docusate), topical antibiotics (rifaximin), and continuous renal replacement therapy (CRRT) if hyperammonemia was $\geq 150 \mu \mathrm{mol} / \mathrm{L}[1,2,13]$. Selection for LT was decided by a multidisciplinary team based on King's College criteria [1, 2, 7].

\section{ONSD Measurement}

ONSD was measured by intensivists (F.S.C., R.P., and N.G.) trained in chest and ONSD ultrasound in critically ill patients using a GE L6 linear transducer, with a frequency of $6.0-13.0 \mathrm{MHz}$, in a GE Vivid ultrasound machine (General Electric). With the patient in a supine position with the head of the bed at 30 degrees, gel was applied on closed eyelids. The transducer was oriented perpendicularly in the vertical plane and at 30 degrees in the horizontal plane to measure the widest transversal ONSD visible $3.0 \mathrm{~mm}$ behind the posterior limit of the eye (Fig. 2) [16, 17, 20, 21]. We obtained 3 measurements over each eye (6 per patient).

The clinicians measuring ONSD were not blinded to the patients' characteristics. While clinicians managing these patients were provided with ONSD measurements, there was no protocol to change care based on ONSD findings.

\section{Exposures and Endpoints}

The primary exposure was ONSD measured at the earliest time-point following ICU admission. Baseline characteristics were collected on the day of ONSD measurement: age (years), sex, body mass index $\left(\mathrm{kg} / \mathrm{m}^{2}\right)$, TBI and ALF etiology; coma grade (GCS); HE grade (West Haven criteria); tympanic temperature $\left({ }^{\circ} \mathrm{C}\right)$, mean arterial pressure ( $\mathrm{mm} \mathrm{Hg}$ ), and urine output $(\mathrm{mL} / \mathrm{h}) ; \mathrm{PaO}_{2} / \mathrm{FiO}_{2}(\mathrm{PF})$ ratio $(\mathrm{mm} \mathrm{Hg}), \mathrm{PaCO}_{2}(\mathrm{~mm} \mathrm{Hg})$, lactate $(\mathrm{mmol} / \mathrm{L})$, platelets $\left(10^{9} / \mathrm{L}\right)$, INR, bilirubin $(\mathrm{mg} / \mathrm{dL})$, ammonia $(\mu \mathrm{mol} / \mathrm{L})$, creatinine $(\mathrm{mg} / \mathrm{dL})$, and sodium (mmol/L) from arterial blood; ICP with intracranial catheter $\left(\right.$ Camino $^{\circledR} 1104 \mathrm{BT}$, Natus ${ }^{\circledR}$ ); CT scan report; use of mechanical ventilation, vasopressors, or CRRT, and Sequential Organ Failure Assessment (SOFA) score [22].

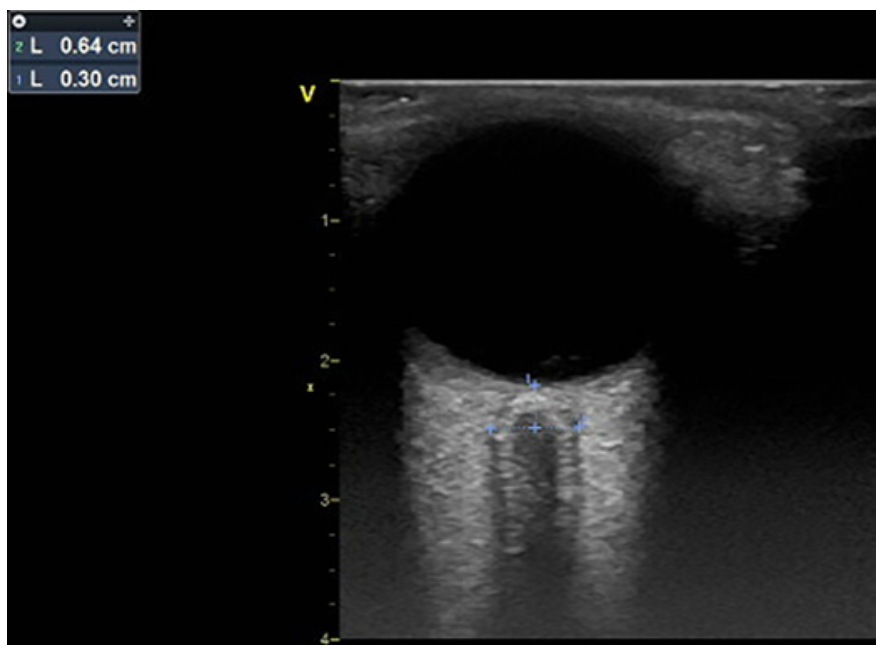

Fig. 2. ONSD measurement.

The primary endpoint was hospital survival. Secondary endpoints were LT during hospital stay and hospital length of stay (LOS). Follow-up ended at 2 months after hospital discharge.

\section{Sample Size Calculation and Interim Analysis}

Based on previous studies, we projected a sample size of $\geq 30$ patients to detect an ONSD difference of $1 \mathrm{~mm}$, with a standard deviation (SD) of $1 \mathrm{~mm}$ and a power of $80 \%$ [16, 17, 20, 21, 23]. Based on a previous study at our center, we expected to include 10-15 cases per year [24]. We prepared an interim analysis following the inclusion of half to two-thirds of the initial target of patients.

\section{Statistical Analysis}

Normally and non-normally distributed continuous variables (Kolmogorov-Smirnov test) are described as the mean \pm SD or median (interquartile range; IQR), respectively. Categorical variables are described as absolute frequency (\%). Missing data across all variables were $3.5 \%$ (difference between intention-to-treat and per-protocol analyses), so multiple imputation was not performed. 
Comparisons among subgroups were performed with the Student $t$, Mann-Whitney, or $\chi^{2} /$ Fisher tests. Unadjusted associations were studied with logistic or linear regression. Discriminative ability was assessed with the C-statistic (95\% confidence interval [CI]). Cut-offs were evaluated based on sensitivity, specificity, negative predictive value, and positive predictive value. Statistical analyses were conducted with IBM SPSS 25 (IBM Corp., North Castle, NY, USA).

\section{Results}

\section{ONSD in Traumatic Brain Injury}

Baseline Characteristics and Outcomes

During September 2018, 8 consecutive patients with TBI and cerebral edema on CT scan were included (online suppl. Table S2). One patient was excluded due to coexistent liver dysfunction.

Among the 8 patients, the mean age was $57 \pm 19$ years and 1 was female (12.5\%; online suppl. Table S3). On the day of ONSD measurement (median of $27.6 \mathrm{~h}$ after ICU admission; IQR 16.2-66.6) 6 patients were in a coma (75.0\%) and the mean SOFA score was $8 \pm 2$. The mean bilateral ONSD was $7.0 \pm 0.6 \mathrm{~mm}$, with very good correlation between right and left eyes (online suppl. Fig. S1; Pearson's $r=0.93 ; p=0.001$ ). Four patients had ICP invasive monitoring with a mean ICP of $14 \pm 3 \mathrm{~mm} \mathrm{Hg}$. There was a non-significant correlation between ONSD and ICP (online suppl. Fig. S2; Pearson's $r=0.90 ; p=$ $0.10)$. F.S.C. performed all of the procedures. ONSD measurements in patients with TBI are detailed in online supplementary Table S4.

Overall, 7 patients $(87.5 \%)$ survived the hospital stay. The patient who died developed ICH with tonsillar herniation. The mean ICU and hospital LOS were $14.7 \pm 5.5$ and $28.8 \pm 27.2$ days, respectively. The baseline characteristics of patients with TBI are depicted in online supplementary Table S3.

\section{ONSD in ALF}

\section{Baseline Characteristics and Outcomes}

From October 2018 to February 2020, 20 patients with ALF were included (intention-to-treat analysis). In 3 patients, ONSD was reported only as the mean right and left values. Because of such protocol violation, the per-protocol analysis included only 17 patients (Fig. 1). Following the inclusion of 20 patients in 17 months, two-thirds of the initial target, we performed an interim analysis and, given its results and slow enrolment, the study was stopped.

Among 20 patients with ALF, the mean age was $45 \pm$ 16 years and 11 were female $(55.0 \%)$. The etiologies of
ALF were: viral in 5 (25.0\%; hepatitis B in 4 and herpes simplex 2 in 1), drug-induced liver injury in 5 (25.0\%; isoniazid in 2 , pyrazinamide in 1 , paracetamol in 1 , and ibuprofen in 1), ischaemia/shock in $4(20.0 \%)$, heat stroke in $1(5.0 \%)$, malignant infiltration in $1(5.0 \%)$, and unknown in $4(20.0 \%)$ patients. The clinical course of ALF was hyperacute in $10(50.0 \%)$, acute in $6(30.0 \%)$, and subacute in $4(20.0 \%)$ patients.

On the day of ONSD measurement (median of $32.4 \mathrm{~h}$ after ICU admission; IQR 19.8-59.8) 8 patients were in a coma (40.0\%), 12 patients $(60.0 \%)$ had grade $3 / 4 \mathrm{HE}$, the mean INR was $3.3 \pm 1.4$, median bilirubin was $12.3 \mathrm{mg} /$ dL (IQR 4.7-24.5), mean ammonia was $163 \pm 101 \mu \mathrm{mol} / \mathrm{L}$, and mean SOFA score was $11 \pm 5$. The mean ammonia was similar between patients with grades $1 / 2$ and $3 / 4 \mathrm{HE}$ (164 vs. $161 ; p=0.94$ ).

The mean bilateral ONSD was $5.6 \pm 0.7 \mathrm{~mm}$, with very good correlation between right and left eyes (online suppl. Fig. S3; Pearson's $r=0.90 ; p<0.001)$. F.S.C. performed $16(80.0 \%)$, N.G. $3(15.0 \%)$, and R.P. 1 (5.0\%) of the procedures. The correlation between ONSD and operator (F.S.C. vs. other) was moderate (Pearson's $r=0.45 ; p=$ 0.047). For all measurements performed by F.S.C., the maximum standard deviations on the right and left eyes were 0.4 and $0.5 \mathrm{~mm}$, respectively. Among 12 patients with grade $3 / 4 \mathrm{HE}, 3$ (25.0\%) had an early CT scan deemed normal. The ONSD measurements in patients with ALF are depicted in online supplementary Table S5.

Overall, 10 patients (50.0\%) were transplanted and 13 (65.0\%) survived the hospital stay. All patients who died had liver-related multiorgan failure and only 1 had clinical suspicion of tonsillar herniation (pupillary dilation). All 13 patients who survived the hospital stay were alive at 2 months after hospital discharge and with a full neurological recovery (extended Glasgow Outcome Scale of 8 [18]).

The mean time from ICU admission to LT was $5.2 \pm$ 2.9 days. The mean ICU and hospital LOS were $9.8 \pm 6.7$ and $26.0 \pm 13.8$ days, respectively. The baseline characteristics of patients with ALF are detailed in Table 1, with no significant differences between intention-to-treat and per-protocol analyses.

\section{Association of ONSD with Endpoints}

The mean SOFA score was significantly higher in hospital non-survivors than survivors both in the intentionto-treat ( 15 vs. $8 ; p=0.002$; Table 2 ) and per-protocol ( 14 vs. $8 ; p=0.004$ ) analyses. The most significant organ dysfunctions in non-survivors were neurological, circulatory, respiratory, and renal (Table 2), with higher propor- 
Table 1. Baseline characteristics of patients with ALF (intention-to-treat and per-protocol analyses)

\begin{tabular}{lcc}
\hline & ALF ITT $(n=20)$ & ALF PP $(n=17)$ \\
\hline Age, years & $45 \pm 16$ & $45 \pm 17$ \\
Female sex & $11(55.0)$ & $9(52.9)$ \\
BMI & $24.2(22.4-29.7)$ & $24.2(22.7-30.7)$ \\
Coma $(\mathrm{GCS} \leq 8)$ & $8(40.0)$ & $6(35.3)$ \\
Grade $3 / 4 \mathrm{HE}$ & $12(60.0)$ & $9(52.9)$ \\
Tympanic temperature, ${ }^{\circ} \mathrm{C}$ & $36.1 \pm 1.1$ & $36.0 \pm 1.1$ \\
PF ratio, mm Hg & $325 \pm 142$ & $330 \pm 152$ \\
PaCO ${ }_{2}, \mathrm{~mm} \mathrm{Hg}$ & $33 \pm 30-37$ & $33 \pm 31-37$ \\
Airway protection or IMV & $8(40.0)$ & $5(29.4)$ \\
MAP, mm Hg & $79 \pm 12$ & $80 \pm 12$ \\
Vasopressors & $8(40.0)$ & $6(35.3)$ \\
Urine output, mL/kg/h & $0.94 \pm 0.74$ & $0.95 \pm 0.77$ \\
RRT & $7(35.0)$ & $6(35.3)$ \\
Lactate, mmol/L & $2.0(1.5-3.3)$ & $2.0(1.3-4.1)$ \\
Platelets, $10^{9} / \mathrm{L}$ & $86(44-153)$ & $90(55-196)$ \\
INR & $3.3 \pm 1.4$ & $3.4 \pm 1.5$ \\
Bilirubin, mg/dL & $12.3(4.7-24.5)$ & $14.1(5.4-24.6)$ \\
Ammonia, $\mu \mathrm{mol} / \mathrm{L}$ & $163 \pm 101$ & $169 \pm 107$ \\
Creatinine, mg/dL & $0.86(0.71-1.46)$ & $0.86(0.72-1.27)$ \\
Sodium, mmol/L & $140 \pm 4$ & $139 \pm 3$ \\
Bilateral ONSD, mm & $5.6 \pm 0.7$ & $5.5 \pm 0.7$ \\
SOFA score & $11 \pm 5$ & $10 \pm 5$ \\
Liver transplant & $10(50.0)$ & $8(47.1)$ \\
Hospital survival & $13(65.0)$ & $11(64.7)$ \\
\hline
\end{tabular}

Data are presented as the mean $\pm \mathrm{SD}, n(\%)$, or the median (IQR). ALF, acute liver failure; ITT, intention-totreat analysis; PP, per-protocol analysis; BMI, body mass index; GCS, Glasgow Coma Scale; HE, hepatic encephalopathy; $\mathrm{PF}, \mathrm{PaO}_{2}$ (oxygen arterial partial pressure)/ $\mathrm{FiO}_{2}$ (oxygen inspired fraction); $\mathrm{PaCO}$, carbon dioxide arterial partial pressure; IMV, invasive mechanical ventilation; MAP, mean arterial pressure; RRT, renal replacement therapy; INR, international normalized ratio; ONSD, optic nerve sheath diameter; SOFA, Sequential Organ Failure Assessment.

tions of coma (71.4 vs. $23.1 \%$; $p=0.06$ ) or vasopressors (71.4 vs. $23.1 \% ; p=0.006$ ), as well as lower mean PF ratio (228 vs. $377 \mathrm{~mm} \mathrm{Hg} ; p=0.020$ ) or urine output (0.42 vs. $1.22 \mathrm{~mL} / \mathrm{h} ; p=0.016)$.

The mean ONSD was significantly higher in patients with coma (6.1 vs. $5.3 \mathrm{~mm} ; p=0.010$ ) or with grade $3 / 4$ HE (5.9 vs. $5.2 \mathrm{~mm} ; p=0.044$ ) in comparison to the others (Fig. 3). The correlation between ammonia and ONSD was poor (Pearson's $r=0.11 ; p=0.64$ ).

The mean ONSD was significantly higher in hospital non-survivors than survivors both in the intention-totreat (6.2 vs. $5.3 \mathrm{~mm} ; p=0.004)$ and per-protocol (6.2 vs. $5.2 \mathrm{~mm} ; p=0.004)$ analyses.

ONSD discriminated well for hospital survival with a C-statistic of 0.86 (95\% CI 0.72-1.00). Accordingly, the possible cut-offs performed as follows: (1) $5.0 \mathrm{~mm}$ had a sensitivity of $100 \%$, a specificity of $46.2 \%$, a negative predictive value of $100 \%$, and a positive predictive value of
$50.0 \%$, and (2) $6.0 \mathrm{~mm}$ had a sensitivity of $71.4 \%$, a specificity of $84.6 \%$, a negative predictive value of $84.6 \%$, and a positive predictive value of $71.4 \%$.

The mean SOFA score was similar between transplanted and non-transplanted patients both in the intention-to-treat (online suppl. Table S6; 10 vs. $11 ; p=0.86$ ) and per-protocol (10 vs. $10 ; p=0.97$ ) analyses. The most significant organ dysfunction in transplanted patients was the liver (online suppl. Table S6), with higher mean INR (4.3 vs. $2.4 ; p=0.001)$ or ammonia ( 212 vs. 114 $\mu \mathrm{mol} / \mathrm{L} ; p=0.026)$. The mean ONSD was similar between transplanted and non-transplanted patients both in the intention-to-treat (online suppl. Table S6; 5.7 vs. $5.6 \mathrm{~mm} ; p=0.82$ ) and per-protocol (5.6 vs. $5.5 \mathrm{~mm} ; p=$ $0.75)$ analyses.

The correlation between ONSD and hospital LOS was moderate both in the intention-to-treat (Pearson's $r=$ $0.53 ; p=0.015$ ) and per-protocol (Pearson's $r=0.57 ; p=$ 
Table 2 Baseline characteristics of patients with ALF stratified by survival status at hospital discharge (intentionto-treat analysis)

\begin{tabular}{lccc}
\hline & Survivors $(n=13)$ & Non-survivors $(n=7)$ & $p$ \\
\hline Age & $39 \pm 14$ & $56 \pm 16$ & 0.020 \\
Female sex & $7(53.8)$ & $4(57.1)$ & 0.99 \\
BMI & $24.2(23.5-29.0)$ & $23.4(19.5-30.9)$ & 0.53 \\
Coma $(\mathrm{GCS} \leq 8)$ & $3(23.1)$ & $5(71.4)$ & 0.06 \\
Grade $3 / 4 \mathrm{HE}$ & $6(46.2)$ & $6(85.7)$ & 0.16 \\
Tympanic temperature, ${ }^{\circ} \mathrm{C}$ & $36.3 \pm 1.1$ & $35.9 \pm 1.2$ & 0.48 \\
PF ratio, mm Hg & $377 \pm 133$ & $228 \pm 107$ & 0.020 \\
PaCO ${ }_{2}, \mathrm{~mm} \mathrm{Hg}$ & $31(30-34)$ & $40(31-43)$ & 0.12 \\
Airway protection or IMV & $5(38.5)$ & $3(42.9)$ & 0.99 \\
MAP, mm Hg & $81 \pm 11$ & $74 \pm 13$ & 0.21 \\
Vasopressors & $3(23.1)$ & $5(71.4)$ & 0.06 \\
Urine output, $\mathrm{mL} / \mathrm{kg} / \mathrm{h}$ & $1.22 \pm 0.67$ & $0.42 \pm 0.59$ & 0.016 \\
RRT & $3(23.1)$ & $4(57.1)$ & 0.17 \\
Lactate, $\mathrm{mmol} / \mathrm{L}$ & $1.7(1.3-2.6)$ & $3.4(1.5-8.5)$ & 0.15 \\
Platelets, $10^{9} / \mathrm{L}$ & $91(46-234)$ & $64(40-82)$ & 0.18 \\
INR & $3.4 \pm 1.5$ & $3.2 \pm 1.4$ & 0.75 \\
Bilirubin, mg/dL & $17.7(5.4-24.4)$ & $10.2(1.5-24.6)$ & 0.73 \\
Ammonia, $\mu \mathrm{mol} / \mathrm{L}$ & $175 \pm 122$ & $141 \pm 39$ & 0.49 \\
Creatinine, $\mathrm{mg} / \mathrm{dL}$ & $0.86(0.64-0.96)$ & $1.57(0.74-2.69)$ & 0.18 \\
Sodium, mmol/L & $139 \pm 3$ & $140 \pm 4$ & 0.66 \\
Bilateral ONSD, mm & $5.3 \pm 0.6$ & $6.2 \pm 0.5$ & 0.004 \\
SOFA score & $8 \pm 4$ & $15 \pm 3$ & 0.002 \\
Liver transplant & $8(61.5)$ & $2(28.6)$ & 0.35 \\
\hline & & & \\
\hline
\end{tabular}

Data are presented as the mean $\pm \mathrm{SD}, n(\%)$, or the median (IQR). BMI, body mass index; GCS, Glasgow Coma Scale; HE, hepatic encephalopathy; $\mathrm{PF}, \mathrm{PaO}_{2}$ (oxygen arterial partial pressure) $/ \mathrm{FiO}_{2}$ (oxygen inspired fraction); $\mathrm{PaCO}_{2}$, carbon dioxide arterial partial pressure; IMV, invasive mechanical ventilation; MAP, mean arterial pressure; RRT, renal replacement therapy; INR, international normalized ratio; ONSD, optic nerve sheath diameter; SOFA, Sequential Organ Failure Assessment.

0.018) analyses. The baseline characteristics of patients with ALF stratified by survival or transplant status at hospital discharge are depicted in online supplementary Tables 2 and S6, respectively.

\section{Adverse Effects of ONSD Measurement}

In both the training and intervention periods, no adverse effects related to ONSD measurements were reported by either the patients or ICU professionals.

\section{Discussion}

\section{Main Findings and Comparisons with Previous \\ Studies}

In our cohort of patients with ALF, the mean ONSD was significantly higher in hospital non-survivors than survivors (6.2 vs. $5.3 \mathrm{~mm}$ ). However, the mean ONSD was similar between patients transplanted and not transplanted (5.7 vs. $5.6 \mathrm{~mm}$ ). The correlation between ONSD and hospital LOS was moderate (Pearson's $r=0.53$ ). ONSD measurements were accurate between both eyes and without adverse effects.

To the best of our knowledge, ONSD measurement by ultrasound in patients with ALF has been investigated in 3 studies [25-27]. Using a prospective cohort of 22 pediatric patients with ALF (30-day survival rate of $45.5 \%$ and LT rate of 81.8\%), Helmke et al. [25] reported an association of higher ONSD with lower survival. In another prospective cohort of 41 pediatric patients with ALF (undefined survival rate of $41.5 \%$ and LT rate of $0 \%$ ), Das et al. [26] also reported an association of higher ONSD with lower survival.

While our findings are consistent with these results, some differences may preclude direct comparisons. Firstly, ONSD measurements in pediatric patients depend on 
Fig. 3. Mean bilateral ONSD stratified by

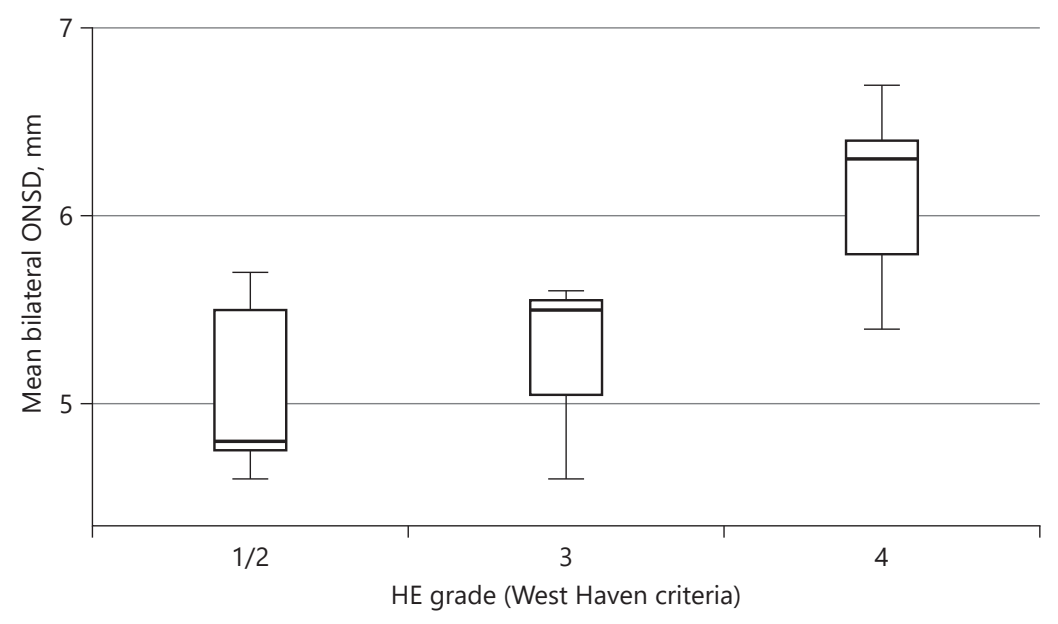
HE grade.

the age interval, likely due to anatomical differences. Secondly, survival and transplant rates were substantially different from ours (hospital survival rate of $65.0 \%$ and LT rate of $50.0 \%$ ). This suggests that these were different cohorts in terms of ALF etiology, course, and severity (SOFA score unavailable in their cohort), as well as LT practice.

Using a retrospective cohort of 41 adult patients with ALF and ICP invasive monitoring (hospital survival rate of $52.2 \%$ and LT rate of $17.4 \%$ ), Rajajee et al. [27] showed that the accuracy of ONSD measurement by ultrasound (C-statistic of 0.59) to detect ICH was lower than that of flow-velocity measurement with transcranial doppler (Cstatistic of 0.90 ). In our cohort, no patient with ALF had ICP invasive monitoring due to the perceived risk of bleeding or infection, as well as the lack of experience in inserting intracranial catheters in this context. Moreover, there is evidence that ICP invasive monitoring may heterogeneously impact the outcomes of patients with ALF $[11,28]$. However, among our 4 patients with TBI and cerebral edema, there was a trend towards very good correlation between ONSD and ICP (Pearson's $r=0.90$ ). Since ONSD measurements had very good correlation between both eyes in the training and intervention periods, we speculate that the correlation between ONSD and ICP in patients with ALF may also be potentially good.

The association of ONSD with coma ( 6.1 vs. $5.3 \mathrm{~mm}$ ) or grade $3 / 4 \mathrm{HE}$ ( 5.9 vs. $5.2 \mathrm{~mm}$ ) in our cohort was consistent with that reported by Das et al. [26]. They showed an increase in median ONSD with HE grade: $4.6 \mathrm{~mm}$ in grade $1,5.2 \mathrm{~mm}$ in grade $2,5.4 \mathrm{~mm}$ in grade 3 , and 5.3 $\mathrm{mm}$ in grade 4 . Likewise, the mean ONSD values in our cohort were: $5.2 \mathrm{~mm}$ in grade $1 / 2,5.2 \mathrm{~mm}$ in grade 3 , and $6.1 \mathrm{~mm}$ in grade 4 .

In our cohort, the correlation between ammonia and ONSD was poor (Pearson's $r=0.11$ ). Das et al. [26] reported a higher but still modest correlation between ammonia and ONSD $(r=0.42)$. In fact, our baseline mean ammonia level $(163 \mu \mathrm{mol} / \mathrm{L})$ was lower than their median ammonia level $(234 \mu \mathrm{mol} / \mathrm{L})$. This may have been due to differences in ALF severity or the use of CRRT to treat hyperammonemia (data unavailable in their cohort). In our cohort, on ONSD measurement, 7 patients (35.0\%) were already on CRRT. Furthermore, ammonia was not significantly different between patients on CRRT and others ( 198 vs. $144 \mu \mathrm{mol} / \mathrm{L} ; p=0.27$ ), suggesting that peak levels may have been worse without CRRT.

The lack of association between ONSD and LT (5.7 vs. $5.6 \mathrm{~mm}$ ) may be explained by the strict selection process for LT. ICH is a contraindication to LT unless resolved. While clinicians were not blinded to ONSD measurements, we cannot clarify if our transplant team weighted such findings in their decisions.

The correlation between ONSD and hospital LOS (Pearson's $r=0.53$ ) may have been affected by the fact that hospital non-survivors had significantly lower hospital LOS than survivors (14.9 vs. 32.0 days; $p=0.005$ ). Patients with a higher mean ONSD died more frequently and spent less time in hospital, weakening the correlation between ONSD and hospital LOS.

The absence of adverse effects related to ONSD measurement by ultrasound reinforces it as an easy to learn (learning curve of $\leq 10$ procedures), widely available 
(transducer in regular ultrasound machine), not timeconsuming ( $\leq 10 \mathrm{~min}$ per patient), and safe technique to perform at the bedside [25-27]. However, the clinical applicability of our findings has to be carefully considered. While a high mean ONSD does not formally diagnose cerebral edema, it may help clinicians to suspect it and start treating it earlier. Nevertheless, several issues remain unresolved and should become the scope of future studies in ALF, for example: compare the value of single and serial ONSD measurements; identify ONSD cut-offs for the diagnosis of cerebral edema or ICH, and compare the efficacy, safety, and practicality of ONSD with other methods to diagnose cerebral edema or ICH, such as cerebral doppler, head CT, head magnetic resonance, or invasive catheter.

\section{Limitations}

The following limitations warrant consideration. Firstly, this was a single-center study, therefore local epidemiology may have influenced our findings. However, the thorough characterization of patients may have minimized such limitation. Secondly, this was a non-blinded study, thus clinicians may have taken into consideration ONSD measurements in their decisions. Thirdly, the lack of systematic head CT scan and invasive ICP monitoring precluded comparisons of ONSD with measures of ICH. Nevertheless, ONSD has been reliable to diagnose ICH in distinct neurocritically ill patients and that may be translated to ALF. Fourthly, as 16 procedures (80.0\%) were performed by 1 investigator, this prevented a better evaluation of the correlation of measurements between observers. However, previous studies have shown that they correlate well among trained individuals [27]. Despite these limitations, we believe our study adds to the literature as there was lack of data supporting the early use of ONSD measurement by ultrasound at the bedside in adult patients with ALF.

\section{Conclusions}

In patients with ALF, a higher ONSD was associated with higher hospital mortality. Early ONSD measurement at the bedside is feasible and safe and has prognostic value.

\section{Acknowledgments}

Thank you to the Liver Failure Group of the Portuguese Intensive Care Society for the institutional support.

\section{Statement of Ethics}

This study protocol was approved by the Ethics Committee at Curry Cabral Hospital (CCH), Central Lisbon University Hospital Center (CLUHC), Lisbon, Portugal (No. 651/2018). Written or verbal informed consent was obtained from participants or their legal representatives. This study abided by the principles of the Declaration of Helsinki and Consort statement.

\section{Conflict of Interest Statement}

The authors have no conflicts of interest to declare.

\section{Funding Sources}

The authors have no funding sources to declare.

\section{Author Contributions}

All authors contributed to the study conception. Design, material preparation, data collection, and analysis were performed by F.S.C. The first draft of the manuscript was written by F.S.C. and all authors commented on versions of the manuscript. All authors read and approved the final manuscript.
References

Optic Nerve in Liver Failure
1 Wendon J, Cordoba J, Dhawan A, Larsen FS, Manns M, Samuel D, et al.; EASL Governing Board representative. EASL Clinical Practical Guidelines on the management of acute (fulminant) liver failure. J Hepatol. 2017 May; 66(5):1047-81.

2 Polson J, Lee WM; American Association for the Study of Liver Disease. AASLD position paper: the management of acute liver failure. Hepatology. 2005 May;41(5):1179-97.

3 Acharya SK, Batra Y, Hazari S, Choudhury V, Panda SK, Dattagupta S. Etiopathogenesis of acute hepatic failure: eastern versus Western countries. J Gastroenterol Hepatol. 2002 Dec; 17(s3 Suppl 3):S268-73.
4 Bernal W, Wendon J. Acute liver failure. N Engl J Med. 2013 Dec;369(26):2525-34.

5 Ostapowicz G, Fontana RJ, Schiødt FV, Larson A, Davern TJ, Han SH, et al.; U.S. Acute Liver Failure Study Group. Results of a prospective study of acute liver failure at 17 tertiary care centers in the United States. Ann Intern Med. 2002 Dec;137(12):947-54.

6 Fix OK, Liou I, Karvellas CJ, Ganger DR, Forde KA, Subramanian RM, et al.; Acute Liver Failure Study Group. Development and Pilot of a Checklist for Management of Acute Liver Failure in the Intensive Care Unit. PLoS One. 2016 May;11(5):e0155500. 
7 Cardoso FS, Marcelino P, Bagulho L, Karvellas CJ. Acute liver failure: an up-to-date approach. J Crit Care. 2017 Jun;39:25-30.

8 Albrecht J, Norenberg MD. Glutamine: a Trojan horse in ammonia neurotoxicity. Hepatology. 2006 Oct;44(4):788-94.

9 Butterworth RF. Pathogenesis of hepatic encephalopathy and brain edema in acute liver failure. J Clin Exp Hepatol. 2015 Mar;5 Suppl 1:S96-103.

10 Bernal W, Hyyrylainen A, Gera A, Audimoolam VK, McPhail MJ, Auzinger G, et al. Lessons from look-back in acute liver failure? A single centre experience of 3300 patients. J Hepatol. 2013 Jul;59(1):74-80.

11 Karvellas CJ, Fix OK, Battenhouse H, Durkalski V, Sanders C, Lee WM; U S Acute Liver Failure Study Group. Outcomes and complications of intracranial pressure monitoring in acute liver failure: a retrospective cohort study. Crit Care Med. 2014 May;42(5):1157-67.

12 Bernal W, Hall C, Karvellas CJ, Auzinger G, Sizer E, Wendon J. Arterial ammonia and clinical risk factors for encephalopathy and intracranial hypertension in acute liver failure. Hepatology. 2007 Dec;46(6):1844-52.

13 Cardoso FS, Gottfried M, Tujios S, Olson JC, Karvellas CJ; US Acute Liver Failure Study Group. Continuous renal replacement therapy is associated with reduced serum ammonia levels and mortality in acute liver failure. Hepatology. 2018 Feb;67(2):711-20.

14 Hansen HC, Helmke K. The subarachnoid space surrounding the optic nerves. An ultrasound study of the optic nerve sheath. Surg Radiol Anat. 1996;18(4):323-8.
15 Hansen HC, Helmke K. Validation of the optic nerve sheath response to changing cerebrospinal fluid pressure: ultrasound findings during intrathecal infusion tests. J Neurosurg. 1997 Jul;87(1):34-40.

16 Robba C, Cardim D, Tajsic T, Pietersen J, Bulman M, Donnelly J, et al. Ultrasound non-invasive measurement of intracranial pressure in neurointensive care: A prospective observational study. PLoS Med. 2017 Jul; 14(7):e1002356.

17 Raffiz M, Abdullah JM. Optic nerve sheath diameter measurement: a means of detecting raised ICP in adult traumatic and non-traumatic neurosurgical patients. Am J Emerg Med. 2017 Jan;35(1):150-3.

18 Carney N, Totten AM, O'Reilly C, Ullman JS, Hawryluk GW, Bell MJ, et al. Guidelines for the management of severe traumatic brain injury, fourth edition. Neurosurgery. 2017; 80(1):6-15.

19 Ho ML, Rojas R, Eisenberg RL. Cerebral edema. AJR Am J Roentgenol. 2012 Sep; 199(3):W258-73.

20 Toscano M, Spadetta G, Pulitano P, Rocco M, Di Piero V, Mecarelli O, et al. Optic nerve sheath diameter ultrasound evaluation in intensive care unit: possible role and clinical aspects in neurological critical patients' daily monitoring. BioMed Res Int. 2017;2017: 1621428.

21 Agrawal A, Cheng R, Tang J, Madhok DY. Comparison of Two Techniques to Measure Optic Nerve Sheath Diameter in Patients at Risk for Increased Intracranial Pressure. Crit Care Med. 2019 Jun;47(6):e495-501.
22 Vincent JL, de Mendonça A, Cantraine F, Moreno R, Takala J, Suter PM, et al. Use of the SOFA score to assess the incidence of organ dysfunction/failure in intensive care units: results of a multicenter, prospective study. Working group on "sepsis-related problems" of the European Society of Intensive Care Medicine. Crit Care Med. 1998 Nov;26(11): 1793-800.

23 Whitley E, Ball J. Statistics review 4: sample size calculations. Crit Care. 2002 Aug;6(4): $335-41$.

24 Simões C, Santos S, Vicente M, Sousa Cardoso F. Epidemiology of Acute Liver Failure from a Regional Liver Transplant Center in Portugal. GE Port J Gastroenterol. 2018 Dec; 26(1):33-9.

25 Helmke K, Burdelski M, Hansen HC. Detection and monitoring of intracranial pressure dysregulation in liver failure by ultrasound. Transplantation. 2000 Jul;70(2):392-5.

26 Das MC, Srivastava A, Yadav RK, Yachha SK, Poddar U. Optic nerve sheath diameter in children with acute liver failure: A prospective observational pilot study. Liver Int. $2020 \mathrm{Feb}$; 40(2):428-36.

27 Rajajee V, Williamson CA, Fontana RJ, Courey AJ, Patil PG. Noninvasive intracranial pressure assessment in acute liver failure. Neurocrit Care. 2018 Oct;29(2):280-90.

28 Rajajee V, Fontana RJ, Courey AJ, Patil PG. Protocol based invasive intracranial pressure monitoring in acute liver failure: feasibility, safety and impact on management. Crit Care. 2017 Jul;21(1):178 